\title{
Regions of Trust and Distrust: \\ How Good Institutions Can Foster Social Cohesion
}

\author{
Nicholas Charron \\ The Quality of Government Institute \\ Department of Political Science \\ University of Gothenburg, Sweden \\ Nicholas.Charron@pol.gu.se
}

and

Bo Rothstein

Blavatnik School of Government and Nuffield College

University of Oxford, United Kingdom

Bo.Rothstein@bsg.ox.ac.uk

Forthcoming in Bernitz, U., Mårtensson, M., Oxelheim, L., and Persson, T. (eds) Bridging the Prosperity Gap in the EU: The Social Challenge Ahead (Cheltenham: Edward Elgar 2017). 


\begin{abstract}
What factors lead to greater levels of generalized trust in society? In this paper, we test four channels through which it is commonly argued trust is affected at the macro level-economic inequality, civic participation, ethnic heterogeneity, and institutional quality. In testing these propositions, the study we report offers the largest and most comprehensive sub-national assessment of this salient question to date, including 206 regions in 25 European countries using data from an original survey of over 85,000 respondents conducted in 2013. Upon mapping national and regional levels of social trust based on our novel data, we find strong variation in levels of generalized trust within many countries, a phenomenon that has been overlooked by national-level studies. We use hierarchical statistical testing to assess the strength of the four channels through which trust can be enhanced or eroded. We find strong and robust evidence that institutional quality-measured as a public sector that allocates services impartially and without corruption-is the strongest determinant of regional variations in trust within countries. Economic inequality is also a robust determinant of trust, but civic participation and ethnic heterogeneity are not significant factors in explaining variations in trust patterns.
\end{abstract}




\section{Institutions, Social Trust and Social Cohesion}

Since the1993 publication of Robert Putnam's modern classic Making Democracy Work, which analyzed the politics of regions in Italy, issues of social capital and social trust have become the object of a huge research industry. Defined as a combination of interpersonal, generalized (that is, social) trust and networks based on reciprocity, social capital is now generally recognized as a major asset for groups and societies (Castiglione et al. 2008; Svendsen and Svendsen 2009). The reason for the strong interest is that a high level of social trust in a society indicates a high level of social cohesion and correlates with a number of other variables that for most people are highly desirable. At the individual level, people who believe that most other people in their society can be trusted are also more inclined to have a positive view of their democratic institutions, participate more in politics, and be more active in civic organizations and are more tolerant towards minorities and to people who are not like themselves. People who are trusting also have a more optimistic view of their possibilities to influence their own life chances and, not least important, to be even more happy with how their life is going (Leung et al. 2011; Helliwell 2006; Dinesen 2013; Delhey and Newton 2005; Uslaner 2002; Freitag and Traunmuller 2009).

The same positive pattern exists at the societal level. Countries with more trusting people are likely to have more functional democratic institutions, more open economies, greater economic growth, and less crime and corruption (Bjørnskov 2009; Keefer and Knack 2005; Richey 2010; Uslaner 2008). Thus, at both the individual and societal levels, many things that are normatively desirable seem connected to social trust and social capital.

With regard to the interpretation of what the standard survey question about social trust actually measures, we support the idea offered by Uslaner (2002), who argues that when people answer whether they think that "most other people can be trusted," their response can be understood as their evaluation of the moral standard of the society in which they live. This implies that trust can be seen as an informal institution, as argued by North (1998), and therefore as a source of social cohesion, creating a system of beliefs that the various groups in society have both a shared responsibility and an ability to provide public and merit goods (Rothstein 2005). 
Our understanding of this research is that there is a nearly general agreement that social trust is beneficial for a society and its individuals. ${ }^{1}$ This book examines the great social challenge the EU currently faces and asks how the Union can secure social cohesion in the aftermath of the economic crisis and large immigration. In this context, there are lessons to be learned from research on social trust. Yet what factors create or erode social trust and social cohesion remains debated. At the aggregate level, a high level of civic participation has been identified as a source of social trust. However, this explanation has been questioned by another group of scholars who have instead pointed to the importance of the quality of government institutions in building social trust. Yet others have pointed to a negative effect of ethnic diversity on social trust and hence on social cohesion. It has also been proposed that social and economic inequality may have a negative effect on social trust.

Building on these previous analyses, this study makes several noteworthy contributions to our understanding of the formation of social trust and social cohesion. First, while comparative empirical research on trust has blossomed in recent years, it has been confined to the country levels, which implies that little is known about how much trust varies within countries, at the regional level. While several analyses investigate trust patterns at the regional or municipal level in a single country (Putnam 1993, 2007; Alesina and La Ferrara 2005; Letki 2008), the question has not been investigated in a multi-country context. We address this gap using original data collected by the authors to explore both generalized trust and institutional quality based on two almost identical large-scale surveys. ${ }^{2}$ The first survey, which was carried out in 2010, included about 34,000 respondents in 172 regions in 24 EU member states (Charron et al. 2013). The second survey was carried out in 2013 and consists of data from some 85,000 respondents in 189 regions in 25 European countries. In total, more than 120,000 respondents have been interviewed, making this the largest empirical investigation on this topic conducted so far. ${ }^{3}$ Combining our survey data with register data for the various regions in the European countries gives us unique opportunities to analyze the effects of several competing explanations of social trust. Moreover, Europe offers an excellent test case due to its remarkable variation in trust at the national level (Hooghe et al. 2009); with our new combination of survey and register data, we show significant variations in trust at the sub-national level, as well, particularly in Italy, Germany, Belgium, Spain, and France. We

\footnotetext{
${ }^{1}$ But see Berman (1997) and Satyanath et al. (2013).

2 The data are in the public domain and can be found at the homepage of the Quality of Government Institute at University of Gothenburg (www.qog.pol.gu.se).

${ }^{3}$ Funding for this research comes in part from the European Commission's Seventh Annual Framework Programme.
} 
can demonstrate that inferences about trust at the regional level are more precise than national-level comparisons. Moreover, sub-national, between-country comparisons provide many advantages, as they increase the number of observations, provide inherent natural controls, and strengthen causal inferences (Snyder 2001).

Before proceeding with our analyses, we present the relevant literature on factors said to increase social trust and strengthen social cohesion. After outlining our specific contribution to this debate, we present our novel data, which constitute to our knowledge the most comprehensive survey to date on social trust and quality of government (QoG). Our results indicate that QoG is far and away the strongest predictor of regional variations in social trust that we have found. We also find that experiences with corruption erode trust much more in high-QoG regions than in those with lower QoG. We conclude with a discussion and suggestions for future research.

\section{What Creates or Destroys Social Trust?}

While the positive effects of high levels of social trust have become generally accepted, several factors relating to how trust is generated have been much debated and become quite controversial. The first, and to a large extent still dominating, view is that social trust is generated by civic participation. Putnam's studies emphasized that citizens learn to develop social trust and understand the importance of positive reciprocity by participating in voluntary associations (Putnam 1993, 2000). According to this society-centered, Tocquevillian approach, the capacity of a society to produce social capital and social trust is determined by citizens' activity in voluntary associations.

However, a large number of studies over the last decades have called into question the effect of civic participation and voluntary associations on social trust. While it is true that people who are joiners also generally trust others more, this seems to be an effect of self-selection; people who score high on the social ability to trust and cooperate with others join voluntary associations disproportionately, but activity in such organizations does not increase the individuals' social trust. Rather, association members become more trusting only of their fellow members, and they cooperate more only for group purposes (Stolle 2003; Uslaner 2002). Thus, the notion that associational membership creates social capital has not survived empirical testing (Armony 2004; Delhey and Newton 2003; Dinesen 2013; Claiborn and 
Martin 2000; Herreros 2004; Robbins 2011; Wollebæck and Selle 2003). To take one example, researchers conducting a large-scale empirical study drawing on World Values Study survey data from no less than sixty countries to explain variations in social trust concluded that "perhaps most important and most surprising, none of the four measures of voluntary activity stood up to statistical tests, in spite of the importance attached to them in a large body of writing, from de Tocqueville onwards" (Delhey and Newton 2004, 27).

As an alternative to the society-centered approach, the institution-centered accounts of social capital theory claim that it is to flourish, social trust must be embedded in and linked to the political context as well as to formal political and legal institutions (Berman 1997; Encarnación 2003; Robbins 2011; Rothstein and Uslaner 2005; Rothstein and Eek 2009; Kumlin and Rothstein 2010; You 2012; Villoria et al. 2013; Richey 2010). According to this line of thinking, it is trustworthy, uncorrupt, honest, and impartial government institutions that exercise public power and implement public policies fairly that create social trust and increase social cohesion. For example, Delhey and Newton found that "government, especially corruption free and democratic government, seems to set a structure in which individuals are able to act in a trustworthy manner and not suffer, and in which they can reasonably expect that most others will generally do the same" $(2004,28)$. Using survey data from 29 European countries, Bjørnskov $(2004,790)$ concluded that a high level of social trust is strongly correlated with a low level of corruption. Analyzing conclusions from their study, also based on comparative survey data, Freitag and Buhlmann (2005) concluded that political institutions that support norms of fairness, universality, and the division of power contribute to the formation of interpersonal trust.

Using scenario experiments in low-trust, high-corruption Romania and in high-trust, lowcorruption Sweden, Rothstein and Eek (2009) found that persons from both countries who experience corruption among public healthcare workers or the local police when traveling in an "unknown city and unfamiliar country" lose trust not only in these authorities but also in people in the unknown society in general. Rothstein and Eek's theory for the causal mechanism between corruption and social trust is that since people cannot really know if "most people" in an unknown society can be trusted, they have to use some kind of shortcut or heuristic to determine how much to trust. Thus, people make inferences from the behavior of public officials when forming beliefs about to what extent people in a society can be trusted. Moreover, if local public officials are known to be dishonest, corrupt, discriminatory, or unfair, many people will make a second inference - namely, that in order to get by in a 
society with dishonest public officials, ordinary people also have to engage in various forms of dishonest behavior (corruption, nepotism, favoritism) and because of this they cannot be trusted.

A major issue in the social trust, social cohesion, and social capital literature has to do with ethnic diversity. The initial positive view of the many good effects of social trust has been challenged by findings showing that societies with a high level of ethnic diversity tend to have lower social trust and that diversity may erode social cohesion (Schaeffer 2013; Putnam 2007; Alesina and La Ferrara 2005). The logic behind this argument is fairly straightforward. People trust other people whom they perceive as ethnically similar to themselves but they distrust people whom they perceive as ethnically different. Some economic studies claim that ethnic diversity, through its negative effects on social trust and social cohesion, explains why many poor countries fail to produce the public goods necessary for social and economic development (Easterly and Levine 1997; Habyarimana et al. 2007). Putnam (2007) and Alesina and La Ferrara (1999) have also reported evidence of this relationship at the subnational level for the United States. Others have claimed that the increasing ethnic diversity in Western Europe will diminish social cohesion, making redistribution to various welfare state programs more difficult (Alesina et al. 2001; Eger 2010). This argument has not gone without criticism and several studies have pointed out that ethnic diversity does not necessarily destroy social trust, or only does so under specific conditions (Banting and Kymlicka 2017; Uslaner 2012; Kumlin and Rothstein 2010; Gesthuizen et al. 2009; Dinesen 2011; Freitag and Traunmuller 2009; Banting 2010). Economic inequality and residential segregation have been offered by Uslaner (2012) as alternative explanations for to the deterioration of social trust

In a recent meta-analysis of the research about ethnic diversity and social cohesion that looked at no less than 480 empirical findings from 172 studies, Schaeffer (2013) showed that many studies about this controversial issue come to different conclusions. This inconclusiveness, according to him, arises from variations in research design, such as which region of the world is examined, what type of ethnic diversity is scrutinized, and what indicators are used to measure social cohesion. Schaeffer points out that while there is a slight overweight for confirmatory studies, discipline matters a lot. Many more studies published in economics journals confirm the negative effect of ethnic diversity on social cohesion than studies published in political science or sociology journals. However, Schaeffer also shows that for the 58 studies that have social trust as the dependent variable in the analysis, the 
results are close to a draw: 30 empirical results refute and 28 corroborate the hypothesis that ethnic diversity is a negative indicator for social trust (Schaeffer 2013, 27-31). Thus, it seems fair to say that the the verdict is still out.

\section{Measuring Social Trust by Country and Region and Exploring Variation at Both Levels}

To capture social trust, we take advantage of a regional QoG survey carried out in 2013 (see Charron et. al. 2015). ${ }^{4}$ The survey samples at what is known in the vocabulary of the European Union as NUTS 1 and NUTS 2 levels. We looked at NUTS regions in 22 European states, ${ }^{5}$ including between 400 and 450 respondents for each such region. The trust question was asked in the standard format used in previous studies, such as the World Values Survey: "Generally speaking, would you say that most people can be trusted or that you can't be too careful in dealing with people in your area?"6

Figure 1 highlights the distribution of social trust by country level ${ }^{7}$ and shows regional variation around each country estimate. Our first result is that social trust varies remarkably across, as well as within, European states. Moreover, while national contexts do matter a great deal, as shown by the consistent clustering of regions around countries, the differences between regions within many EU countries are noteworthy and clearly demonstrate the limits of previous national-level analyses.

While the grand sample mean score for trust is 0.425 , we also find noteworthy national-level variation, as many earlier studies have shown. While Scandinavian states display very high levels of social trust, several EU member countries, like France and Poland, display surprisingly low levels. To some degree, social trust appears to be determined by geography or history (that is, western vs. eastern Europe), yet we observe that some of the "old" western EU countries such as France, Greece, Portugal, and Belgium have no regions where more than half of the respondents state they are "trusters" (with a trust score above 0.5, as shown

\footnotetext{
4 For a description of the survey, codebook and access to the data, please see http://qog.pol.gu.se/QoGinstitutet/data/nedladdningsbaradatamängder/qogeuregionaldata

5 NUTS stands for "nomenclature of territorial units for statistics; more can be read about them at http://epp.eurostat.ec.europa.eu/portal/page/portal/nuts_nomenclature/introduction.

${ }^{6}$ At the individual level, the response "Most people can be trusted" is coded as 1 and "Can't be too careful" is coded as 0 . At the regional level, we take the proportion of respondents who answered "Most people can be trusted" over those who answered "Can't be too careful," such that aggregate responses over 0.5 indicate that the majority of people in a region believe that most people can be trusted, while a result less than 0.5 indicates that a majority believes that one "can't be too careful." The measure is continuous and bound between 0 and 1 .

${ }^{7}$ Country levels are calculated as a population-weighted average of the regional-level scores for each country. Population data by region taken from Eurostat.
} 
by the dashed line in Figure 1). At the country level, the vast majority of respondents in Sweden and Denmark, as well as in the United Kingdom, Finland, Austria, Ireland, and the Netherlands say that they trust others, yet social trust is extremely low in several other European states. For example, in Hungary, Greece, Bulgaria, and most regions in France, less than 30 percent of respondents say that they feel they can trust others. In the Czech Republic, Slovakia, and Serbia, this number drops below 20 percent. When we compare these data with other recent empirical analyses, we find our country-level estimates to be highly consistent with those from alternative data sources. ${ }^{8}$

The regional-level variation across Europe is striking, with trust scores ranging from 0.08 (for the Východné Slovensko region in Slovakia) to a stunning 0.80 (the Copenhagen region in Denmark). This means that, at the extreme, the difference in social trust between regions in Europe is tenfold. Moreover, several countries, such as Italy, Spain, Germany, Austria, France, and Belgium, have noteworthy regional variation in social trust within the country, while others, such as Slovakia, Denmark, and Poland, do not.

In Germany, the region with the highest level of social trust, Schleswig-Holstein, is among the top 10 percent in our full sample of regions, with a vast majority of respondents claiming that they can trust others. But in Saarland, a German region close to France, the trust score is far below the sample average, with less than 34 percent of respondents feeling that they can trust others. We find a similarly large gap in Italy, with Friuli Venezia-Guilia and Bolzano in the north showing quite high levels of social trust while Campania in the mezzogiorno south stands out as relatively low. Germany and Italy both have regions that have the same levels of social trust or higher as those found in Finland, Austria, or the United Kingdom, while several regions in these countries have lower social trust indicators than regions in Portugal, Romania, Spain, Belgium, or Poland-all countries with noticeably lower levels of trust at the national level. Spain and Belgium also have noteworthy variation, with social trust in Flanders almost twice as high as it is in Wallonia. For Spain, the majority of respondents in the País Vasco region trust others (54 percent), while less than 38 percent do in the Canarias or Murcia regions.

\section{****Figure 1 about here ${ }^{* * * *}$}

\footnotetext{
${ }^{8}$ For example, two recent studies employ a European, or largely European sample (Hooghe et al. 2009; Freitag and Buhlmann 2009). The Spearman rank coefficients between our common countries and theirs are 0.85 and 0.86 , respectively.
} 
While regional-level comparisons are more scarce, these findings are generally consistent with previous studies that have explored social trust at the regional level in Europe (Tabellini 2010; Van Schaik 2002) and correlate rather strongly with the most recent round of the European Value Survey (EVS) at the regional level. To provide a further test of external validity, we gathered trust data from the latest round of the EVS (2008), which is available at the same regional level we used and which uses the exact same trust question we have. We find that among the 182 regions our data and the EVS have in common, the Spearman rank coefficient is 0.58. However, many regions in the EVS data have insufficient observations (less than 100); when comparing only regions that have at least 100 observations in the EVS (117 total), the Spearman rank coefficient increases to 0.70 . When comparing the 68 regions that have at least 200 observations in the EVS, the Spearman rank increases to 0.79, demonstrating that the estimates begin to converge as the sample size increases, which provides evidence of external validity for our measure. However, we would argue that the data we have collected are more representative and thus more reliable than regional data used in previous studies, as the sample size per region we have is more than twice that of the EVS or the World Value Survey. ${ }^{9}$ Our survey also has the advantage of having data points from the same year, as opposed to the other surveys, which have data merged in rounds of two- to three-year periods.

To test whether any pairwise within-country regional differences are significant, we constructed confidence intervals (95 percent) around each region's estimate. ${ }^{10}$ In 13 of the 22 countries we examined, there is at least one pairwise distinction, while in 9 of the countries, there is no pairwise significant difference between any of the regions. We then calculate a population-weighted Gini index of regional inequality for each country (see appendix). In Figure 2, we highlight the three countries with the most and the three with the least regional variation in generalized trust, showing highly significant variation in Belgium, Italy, and Germany, and none in Sweden, the Netherlands, and Slovakia.

\footnotetext{
${ }^{9}$ Using EVS data instead of ours for the 189 regions in common with our study would result in about 40,000 fewer individual observations $(31,368$ compared with 72,800) or an average regional $N$ of 175 compared with 410 for our study.

${ }^{10}$ Our estimate is a proportion $(p)$ of trust per region; thus, the formula to construct the standard error is $s e=$ $\sqrt{\frac{p(1-p)}{n}}$. In most cases, $n$ is roughly 400. The standard error is then added to 1.96 and added/subtracted from each region's estimate of trust to calculate the 95 percent confidence interval.
} 
How much of the total variation in generalized trust is explained at the regional and country levels? To calculate this, we ran an empty ("intercept only") hierarchical model with the regional level of trust as the dependent variable, accounting for country-level random intercepts. The results demonstrate that the regional level accounts for 22 percent and the country level accounts for 78 percent of the geographical variation in generalized trust in Europe. Thus, although the country context is highly relevant, a sizeable portion of the variation is left unexplained if one ignores the regional level, particularly in those states with high levels of within-country variation, such as Germany, Italy, and Belgium.

\section{Regional-Level Differences in Social Trust: Explanatory Variables and Methods}

In this section, we model statistically several leading explanations of social trust. While register and survey data at the sub-national level is growing in relevance, it still cannot compare in terms of scope and availability to national-level register and survey data; thus, we are somewhat limited in our selection of indicators. An appendix with the key data used for each region can be found at the homepage of the Quality of Government Institute. ${ }^{11}$

a. Quality of public-sector institutions. For this variable (QoG), we use the survey we carried out in 2010, from which we calculated a regional score labeled the European Quality of Government Index (EQI; Charron, Dijkstra, and Lapuente 2014). Using the earlier data set ensures that the data on social trust and the data on experiences and perceptions of institutional quality are not from the same respondents, avoiding the problem of simultaneity. It is also an advantage that the measure of this independent variable precedes the measure of the dependent variable (social trust). The EQI measure captures the extent to which regional public services are impartial, of high quality, and free from corruption, based on the experiences and perceptions of our citizen-respondents. To maximize the importance of the regional level, the data focus on services primarily administered or financed by sub-national actors, such as public education, public health services, and law enforcement. The survey also included questions about the extent to which regional elections were perceived as being free

\footnotetext{
${ }^{11}$ http://qog.pol.gu.se/data/datadownloads/qogeuregionaldata. All data can be freely download from this source
} 
from corruption and the level of perceived political impartiality in the regional mass media. From this, we created a regional index for the survey as a whole as well as for several subcomponents, such as impartiality and corruption. ${ }^{12}$

b. Economic Inequality. While inequality measures such as the Gini index, the Theil index, $90 / 10$ or $80 / 20$ ratios of income earners, or median-to-mean income are now widely available at the national level, such measures are unfortunately scarcer at the sub-national level for the wide sample of countries. Fortunately, one valid measure is available for all regions in our sample - the percent of the population at risk of poverty (after social transfers) from Eurostat (2008). This at-risk-of-poverty measure is calculated as having "an equivalized disposable income (that is, adjusted for household size and composition) of less than 60 percent of the national median" (EU Commission Cohesion Report 2010). ${ }^{13}$ While this does not show the extent to which the very rich are wealthier than the middle class, it represents a clear and comparable measure of the extent to which economic inequality affects those at the bottom of the income ladder across regions.

c. Voluntary civic participation and social networks. We capture civic participation and social networks with two measures. First, taking survey data from the latest round of the EVS (2008), we combined six relevant questions about voluntary civic participation into one index. ${ }^{14}$ For each of the six items, we took the aggregate proportion of 'yes' responses and, after obtaining weights from a principle component factor analysis (PCF), we combined the six items into a single index (the civic index) for each region. ${ }^{15}$ The index ranges from 0 (no

\footnotetext{
${ }^{12}$ For purposes of robustness, we employ an alternative "hard measure" that captures public-sector institutional quality more broadly. While there is no perfect measure available to capture this concept, as a proxy for the quality and effectiveness of regional public-sector institutions, we take a measure of health outcomes that is commonly associated with quality health services, namely the average life expectancy from less than one year old, averaged for the five-year period 2008-2012. The measure is then standardized (as is the EQI). The correlation between the EQI measure and life expectancy is $0.48(\mathrm{p}=0.0000, \mathrm{n}=206)$. A possible alternative might have been aggregate student scores on math, reading, and science in the international PISA tests, but these are not available at the regional level in most countries.
}

\footnotetext{
${ }^{13}$ Comparing this measure to a recent study that constructed several measures of inequality for regions within four countries-France, the Czech Republic, Italy, and Spain-we find that the measure of the population in poverty correlates very highly with the median/mean income measure (between 0.81 and 0.94 in the four countries).

${ }^{14}$ The six participation items were captured in the EVS in a single question: "Which, if any, do you belong to? A) Political parties or groups B) Religious or church organizations C) Education, arts, music or cultural activities D) Sports or recreation E) Local community action on issues like poverty, employment, housing, racial equality F) Other groups."

${ }^{15}$ The PCF showed all 6 components clustered strongly onto one factor (according to the Kaiser criteria), as there was only one factor with an Eigenvalue over 1 and it explained over 60 percent of the total variation.
} 
participation) to 1 (full participation in all activities). A full description of the index's construction, the weights, and other specifics can be found in the appendix.

Second, we use the voter turnout in regional parliamentary elections, averaged for all available electoral data from 1990 to 2010 . Since these are not national elections, they give an even better sense of how much civic engagement can vary from region to region as well as how engaged citizens are in local politics.

d. Ethnic diversity. While most data on population heterogeneity is available only at the national level, the extent to which regions are ethnically homogenous or heterogeneous is captured with two measures. First, we employ a measure from Eurostat, the percentage of each region's population born outside of the EU. This measure is constructed by adding together all residents of each included regions who were born in Africa, Asia, the Americas, and Oceana and dividing them over the region's total resident population. To capture the degree to which ethnic heterogeneity varies by region, we take the measure of regional ethnic diversity from Alesina and Zhuravskaya (2011), calculating the percentage of the population that belongs to the main ethnic group for each region. While the first measure is comprehensive, the second is limited to roughly 90 regions in the sample.

We also include in our analysis several other structural factors elucidated by the literature, including a measure of the extent to which politics in a region is polarized or competitive. From regional elections data, ${ }^{16}$ we calculated several measures of elite, political competition. First, we capture the extent to which regional parliamentary elections are competitive, based on a common measure from the literature on party competition, the vote percent difference between the two largest parties in a given election (Jackman 1987). ${ }^{17}$ Second, we created a regional measure of party fractionalization. This is calculated using a Herfindal index, which essentially elucidates the likelihood of randomly drawing out two members of parliament (MPs) of the same political party, with scores ranging from 0 to 1 . A score of 0 indicates that all MPs are of different parties, while a score of 1 indicates that all MPs belong to the same party. On this scale, we take ' 1 -Herfindal' to render higher numbers equaling more fractionalization.

\footnotetext{
${ }^{16}$ Data taken from http://www.parties-and-elections.eu/.

${ }^{17}$ In the case of some regions, primarily in Italy where parties announce other parties with whom they will form a coalition before Election Day, we take the difference between the two largest pre-election coalition blocs.
} 
Finally, in keeping our model as parsimonious as possible, we control for the level of economic development, captured by taking the average logged GDP (PPP), per capita income (averaged) for 2007-2009 (Eurostat). We also control for region size, in terms of both population and area, using a measure of population density (Eurostat) from 2010, logged. We expect from previous research that higher development is associated with higher trust, while more-urban areas will have lower levels of trust on average. Further, we check whether a region's being a capital or whether it is autonomous or not $(0 / 1)$ plays a role in determining variation in levels of regional trust. ${ }^{18}$

Our sample is derived from a survey of over 85,000 individuals in 212 NUTS 1 and NUTS 2 regions in 25 European countries. ${ }^{19}$ Due to the limitations of register data at the regional level, countries like Ukraine, Turkey, and Serbia are dropped from most models. For models testing QoG, inequality, and diversity, we have between 181 and 189 regions in 21 countries. Data on civic engagement are more limited, and several countries drop out, reducing the number of regions in these models.

Moreover, the political and administrative relevance of the NUTS regions varies by country. In some cases, such as Spain, Belgium, Denmark, Poland, and Germany, the regional level in the data corresponds directly with politically meaningful units that have elected parliaments and exercise policy control over several areas, such as health care and education. Others, however, such as the NUTS units in Sweden, Bulgaria, Romania, and Portugal, are simply statistical units whose borders are drawn by the EU Commission. We check the results via limited samples that include only politically relevant regions ( $p r r$, which are coded as all regions in Italy, Germany, Spain, Denmark, Belgium, Poland, France, and Austria; three regions from the United Kingdom (Scotland, Wales, and Northern Ireland); and two from Portugal (Açores and Madeira). When testing the variables of political fractionalization and competitiveness along with civic engagement, we have data only for politically relevant regions, which reduces the number of participating regions to 125 .

\section{Results}

\footnotetext{
${ }^{18}$ We find, however, that the latter two variables are mostly insignificant factors and fail to improve model strength in a post regression comparison (LR test); thus, they are not reported in the main tables.

${ }^{19}$ A full list of regions in the sample is in Appendix A. NUTS refers to "Nomenclature of territorial units for statistics"; these are EU-defined statistical regions. For more information, see http://epp.eurostat.ec.europa.eu/portal/page/portal/nuts_nomenclature/introduction.
} 
Figure 3 shows the scatter plot and a fitted linear relationship between the two variables. The scatterplot confirms the general expectation of a positive and significant relationship between these two factors, with the bivariate regression accounting for 25 percent of the variation in regional trust. We notice, however, that the relationship is not consistent across all values of our European Quality of Government Index (EQI), largely due to country effects. Slovak and Czech regions for example, which have EQI scores at or slightly below the mean, have much lower trust scores than the bivariate model would predict. On the other end, several regions in Southern Italy have much higher levels of generalized trust than would be predicted by the EQI.

\section{****Figure 3 about here ${ }^{* *}$}

Issues of endogeneity or reverse causality are ever-present in cross-sectional studies, and our study is no exception. Although it is not a perfect remedy, we address this by taking all independent variables temporally prior to our measurement of TRUST. ${ }^{20}$ In addition, as Figure 3 shows, the data are heterogeneous and diagnostic checks confirm this-in particular for several of the key variables, such as QoG and inequality-with much more variation in the dependent variable at low levels of the key explanatory factors than at high levels. That the observations are not independent can of course be driven by sub-population differences (e.g., countries) and can result in biased estimates. We account for this in the models, electing to model the data in two ways-hierarchically as well as with country-fixed effects in OLS estimation, both reported in Table 1. A visual scatterplot of the other main indicators (economic inequality, civic participation, and ethnic heterogeneity) can be found in the appendix.

Overall, our main finding is that there is strong and consistent support for the hypothesized relationship between institutional quality and social trust. Controlling for the region's level of economic development and population size (density, logged), we find that the marginal effect of a one standard deviation increase in the EQI results in an expected increase in regional social trust of 4 percent, holding all other variables constant. Economic development and population density are significant positive and negative predictors, respectively, of regional variation in trust.

\footnotetext{
${ }^{20}$ See the appendix for the dates of measurement for each variable.
} 
In our study, we also examine if other factors are systematically related with levels of trust at the regional level in Europe. While diversity's effect is in the negative direction, that effect becomes negligible when controlling for economic development, population size, and QoG. We do find however that the measure of economic inequality is a significant predictor of levels of trust. For example, an increase of 10 percent in the regional poverty risk results in an expected decrease in social trust of 2.3 percent. Our measure of civic participation, also has a slight positive effect on trust levels. We find that even when re-estimating the results with country-fixed effects, the findings are mostly indistinguishable from the results reported above, with the exception of the coefficient estimate of civic participation, which becomes insignificant. . In addition, we run a number of robustness checks whereby we use alterantive measures of our concepts, use various weights for the obsevations, remove outliers, and estimate only regions in countries that have sizeable trust gaps. The effect of QoG on social trust, however, is significant at the 99 percent level of confidence throughout all the models.

\section{The Quality of Public Instituions Matters for Social Cohesion}

Social trust has been shown to be a highly relevant and beneficial societal characteristic. In this study, we make two significant contributions to the literature explaining variations in social trust and social cohesion. First, we present the most comprehensive data on social trust available to date for European countries and regions. When mapping generalized trust at and below the country level, we find significant variation that has been overlooked by previous data limitations that have driven country-level analyses. While we find the country-level analyses remain highly relevant, regional variation represents a significant minority of the overall spatial variation in trust across Europe-in particular in several (mostly federal) countries, such as Belgium, Germany, Italy, and Spain. Moreover, we find significant regional differences even in non-federal countries, such as France, Poland and even Romania and Portugal, suggesting that sub-national patterns of social trust are not determined exclusively by the boundaries of sub-national political units.

Second, using our novel data, we test several of the main theoretical propositions regarding what explains variations in social trust using our novel data. Our argument is that testing even established theories at multiple levels is salient for developing stronger empirical relationships and ruling out potential issues of spuriousness. We tested the theory of the relation between the quality of government (QoG) and social trust against several other 
theoretical propositions (such as the effects of economic inequality, civic participation, ethnic diversity, and political environment). Our central finding is that QoG is a highly robust predictor of aggregate levels of social trust at the regional level, both within and across countries. We show that the results are highly robust to multiple model specifications, alternative measures of the concepts, observation weights, and various sample specifications.

Previous research at the national level has found support for the theory that low-corruption, high-QoG institutions are associated with higher levels of social trust across countries; that argument is strengthened by these findings at the sub-national level. We would argue that the regional lens we have used is preferred test for several reasons, most significantly that cultural and institutional differences that are difficult to capture in cross-country tests are naturally controlled for when comparing regions within countries.

We also confirm results from several other studies showing that activity and membership in voluntary associations have negligible effects on the propensity for individuals to trust other people. More surprising is that the effects of ethnic diversity on social trust turns out to be negligible when controlling for QoG. Since all the studies we have seen that have shown a negative effect of ethnic diversity on social trust have left out variables measuring institutional quality, our finding is of some importance. This study has thus taken an additional step in furthering our understanding of spatial variations in generalized trust across and within countries.

However, our measure of economic inequality remained a robust indicator of generalized trust along with QoG, suggesting that the two factors are relevant at the country as well as sub-national levels. As for shedding light on future theory, based on experimental research about the importance of reciprocity for social solidarity and social cohesion (Gintis et al. 2005; Henrich 2004; Svallfors 2013), we would suggest an explanation for the importance of QoG for social trust in regions along the following lines. If a person living in an EU region with low QoG experiences an influx of immigrants from either inside or outside Europe, this person may come to think that because QoG is low, the new residents will get away with various types of opportunistic behavior, such as tax avoidance and overuse or abuse of social services. Thus, people in general cannot be seen as worthy of trust. However, if QoG in the region is high, the same person may think that although the newcomers are "different," because of high institutional quality they are likely to follow the rules; thus, most people in 
these high-QoG regions a more likely to think that most people in general, including the newcomers, can be trusted.

To conclude, we suggest that the EU and its member countries need to focus on improving the quality of public-sector institutions and fighting corruption if social cohesion is to be enhanced. Although this is not an easy fix, according to our results it is the best way to bridge the growing prosperity gap and handle the increased socio-economic inequality in Europe.

\section{References}

Alesina, Alberto, Edward L. Glaeser, and Bruce Sacerdote (2001), 'Why doesn't the United States have a European-style welfare state?' Harvard Insitute of Economic Research, Discussion paper 1933.

Alesina, Alberto, and Eliana La Ferrara (2005), 'Ethnic diversity and economic performance', Journal of Economic Literature 43 (3), 762-800.

Armony, Ariel C. (2004), The dubious link: Civic engagement and democratization. Stanford, CA: Stanford University Press.

Banting, Keith G. (2010),'Is There a Progressive's Dilemma in Canada? Immigration, Multiculturalism and the Welfare State', Canadian Journal of Political Science-Revue Canadienne De Science Politique 43 (4), 797-820.

Banting, Keith G. and Will Kymlicka (2017). The Strains of Commitment: The Political Sources of Solidarity in Diverse Societies. Oxford: Oxford University Press (in press)

Berman, Sheri (1997), 'Civil Society and the Collapse of the Weimar Republic', World Politics 49 (3), 401-429.

Bjørnskov, Christian (2009), 'Economic Growth', In Handbook of Social Capital, ed. G. T. Svendsen and G. L. H. Svendsen. Cheltenham: Edward Elgar, pp.337-353.

Castiglione, Dario, Jan van Deth, and Guglielmo Wolleb (eds.) (2008), Handbook of Social Capital. Oxford: Oxford University Press.

Charron, Nicholas, Victor Lapuente, and Bo Rothstein (2013), Quality of Government and Corruption from a European Perspective: A Comparative Study of Good Government in EU regions. Cheltenham: Edward Elgar.

Charron, Nicholas, Lewis Dijkstra and Victor Lapuente (2014), 'Regional Governance Matters: Quality of Government within European Union Member States', Regional Studies, 48 (1), 6890.

Charron, Nicholas., Lewis Dijkstra, and Victor Lapuente (2015), Mapping the regional divide in Europe: A measure for assessing quality of government in 206 European regions. Social Indicators Research, 122 (2), 315-346.

Claiborn, Michele P, and Paul S Martin (2000), 'Trusting and joining? An empirical test of the reciprocal nature of social capital', Political Behavior 22 (4),267-91.

Delhey, Jan, and Kenneth Newton (2003), 'Who trusts? The origines of social trust in seven societies', European Societies 5 (2),93-137.

Delhey, Jan, and Kenneth Newton (2004), 'Social Trust: Global Pattern or Nordic Exceptionalism', Berlin: Wissenschaftszentrum Berlin für Socialforschung.

Delhey, Jan, and Kenneth Newton (2005), 'Predicting cross-national levels of social trust: Global pattern or nordic exceptionalism?' European Sociological Review 21 (4), 311-27. 
Dinesen, Peter Thisted (2013), 'Where You Come From or Where You Live? Examining the Cultural and Institutional Explanation of Generalized Trust Using Migration as a Natural Experiment', European Sociological Review 29 (1),114-28.

Easterly, William, and Ross Levine (1997), 'Africa's Growth Tragedy: Policies and Ethnic Divisions." The Quarterly Journal of Economics 112 (4), 1203-50.

Eger, Maureen A. (2010), "Even in Sweden: The Effect of Immigration on Support for Welfare State Spending." European Sociological Review 26 (2), 203-17.

Encarnación, Omar G. (2003), The Myth of Civil Society. Social Capital and Democratic Consolidation in Spain and Brazil. New York: Palgrave/Macmillan.

Freitag, M., and R. Traunmuller (2009), 'Spheres of trust: An empirical analysis of the foundations of particularised and generalised trust', European Journal of Political Research 48 (6), 782-803.

Freitag, Markus, and M. Buhlmann (2005), 'Political institutions and the formation of social trust. An international comparison', Politische Vierteljahresschrift 46 (4), 575-86.

Gesthuizen, Maurice, Tom van der Meer, and Peer Scheepers (2009), 'Ethnic Diversity and Social Capital in Europe: Tests of Putnam's Thesis in European Countries', Scandinavian Political Studies 32 (2): 121-42.

Gintis, Herbert, Samuel Bowles, Robert Boyd, and Ernst Fehr (eds.) (2005), Moral Sentiments and Material Interests. The Foundations for Cooperation in Economic Life. Cambridge, Mass.: The MIT Press.

Habyarimana, James, Macartan. Humphreys, David N. Posner, and Jeremy. M. Weinstein (2007), 'Why does ethnic diversity undermine public goods provision?' American Political Science Review 101 (4), 709-25.

Helliwell, John F (2006), 'Well-being, social capital and public policy: What's new?' Economic Journal 116, C34-C45.

Henrich, Joseph Patrick (2004), Foundations of human sociality: Economic experiments and ethnographic evidence from fifteen small-scale societies. Oxford New York: Oxford University Press.

Herreros, Francisco (2004), The Problem of Forming Social Capital, Why Trust? New York: Palgrave/Macmillan.

Hooghe, Marc, Tim Reeskens, Dietlind Stolle, and Ann Trappers (2009), 'Ethnic Diversity and Generalized Trust in Europe A Cross-National Multilevel Study', Comparative Political Studies 42 (2), 198-223.

Keefer, Philip, and Stephen Knack (2005), 'Social Capital, Social Norms and the New Instituitonal Economics', In Handbook of New Institutional Economics, ed. C. Menard and M. M. Shirley. Amsterdam: Springer, pp. 701-725.

Kumlin, Staffan, and Bo Rothstein (2010), 'Questioning the New Liberal Dilemma, Immigrants, Social Networks and Institutional Fairness', Comparative Politics 41 (1), 63-87.

Letki, Natalia (2008), 'Does diversity erode social cohesion? Social capital and race in British neighbourhoods', Political Studies 56 (1), 99-126.

Leung, Ambrose, Cheryl Kier, Tak Fung, Linda Fung, and Robert Sproule (2011), 'Searching for Happiness: The Importance of Social Capital', Journal of Happiness Studies 12 (3), 443-62.

North, Douglass C (1998), 'Economic Performance Through Time', In The New Institutionalism in Sociology, ed. M. C. Brinton and V. Nee. New York: Russell Sage Foundation.

Putnam, Robert D. (1993), Making Democracy Work: Civic Traditions in Modern Italy. Princeton: Princeton University Press.

Putnam, Robert D. (2000), Bowling Alone: The Collapse and Revival of American Community. New York: Simon and Schuster.

Putnam, Robert D. (2007), 'E pluribus unum: Diversity and community in the twenty-first century the 2006 Johan Skytte Prize Lecture', Scandinavian Political Studies 30 (2), 137-74.

Richey, Sean (2010), 'The Impact of Corruption on Social Trust', American Politics Research 38 (4), 676-90.

Robbins, Blaine G. (2011), 'Neither government nor community alone: A test of state-centered models of generalized trust', Rationality and Society 23 (3), 304-46.

Rothstein, Bo (2005), Social Traps and the Problem of Trust. Cambridge: Cambridge University Press. 
Rothstein, Bo, and Daniel Eek. 2009. 'Political Corruption and Social Trust - An Experimental Approach', Rationality and Society 21 (1), 81-112.

Rothstein, Bo, and Eric M. Uslaner (2005), 'All for All. Equality, Corruption and Social Trust', World Politics 58 (3), 41-73.

Schaeffer, Merlin (2013), 'Ethnic diversity, public goods provision and social cohesion. Lessons from an inconclusive literature', Berlin: WZB Social Research Center, Discussion paper SP V 2013-103.

Stolle, Dietlind (2003), 'The Sources of Social Capital', In Generating Social Capital: Civil Society and Institutions in a Comparative Perspective, ed. M. Hooghe and D. Stolle. New York: Palgrave/Macmillan, pp. 272-203.

Svallfors, Stefan (2013), 'Government quality, egalitarianism, and attitudes to taxes and social spending: a European comparison', European Political Science Review, 5 (3), 363-80.

Svendsen, Gert T., and Gunnar L. H. Svendsen (2009), Handbook of social capital: The troika of sociology, political science and economics. Cheltenham, Edward Elgar.

Uslaner, Eric M. ( 2002), The Moral Foundation of Trust. New York, Cambridge University Press.

Uslaner, Eric M. (2008), Corruption, inequality, and the rule of law : the bulging pocket makes the easy life. Cambridge: Cambridge University Press.

Uslaner, Eric M. (2012), Segregation and mistrust: Diversity, isolation, and social cohesion. Cambridge: Cambridge University Press.

Villoria, Manuel, Gregg G. Van Ryan, and Cecilia F. Lavena (2013), 'Social and Political Consequences of Administrative Corruption: A Study of Pulblic Perceptions in Spain." Public Administration Review 73 (1), 85-94.

Wollebæck, Dag, and Per Selle (2003), 'Participation and social capital formation: Norway in a comparative perspective.' Scandinavian Political Studies 26 (1), 67-91.

You, Jong-sun (2012), 'Social Trust: Fairness Matters More Than Homogeneity', Political Psychology 33 (5), 701-21.

\section{Figure 1}

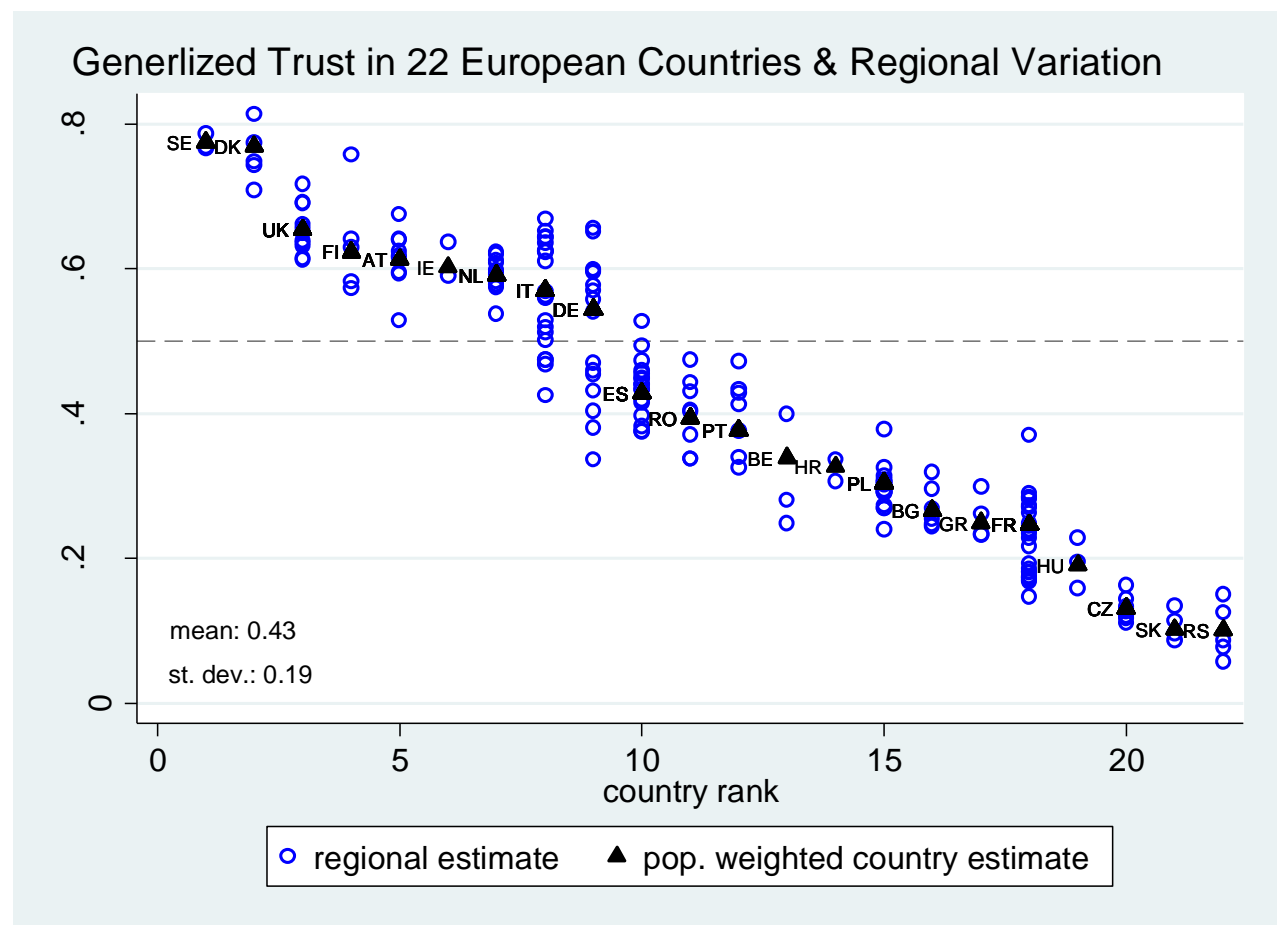




\section{Figure 2}

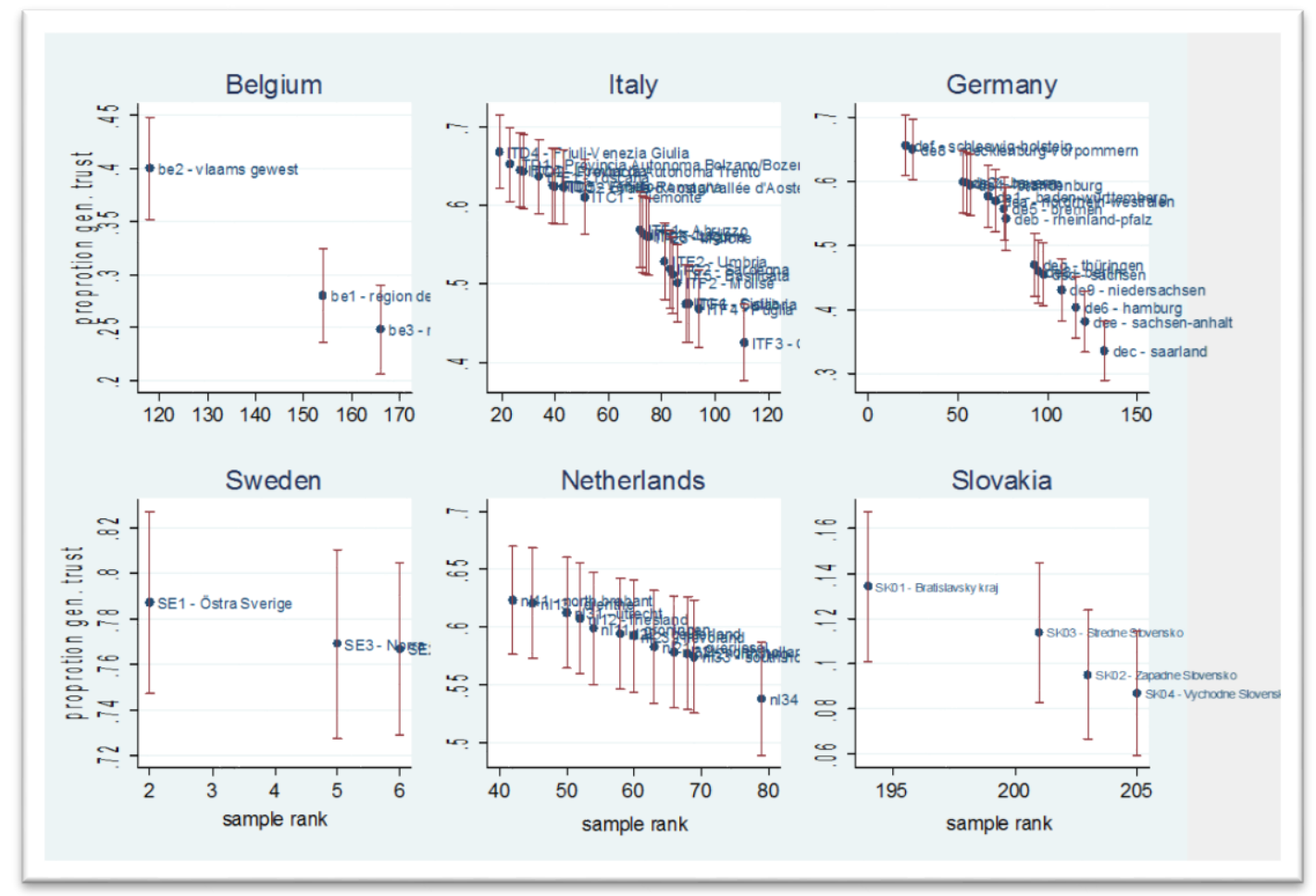

\section{Figure 3}

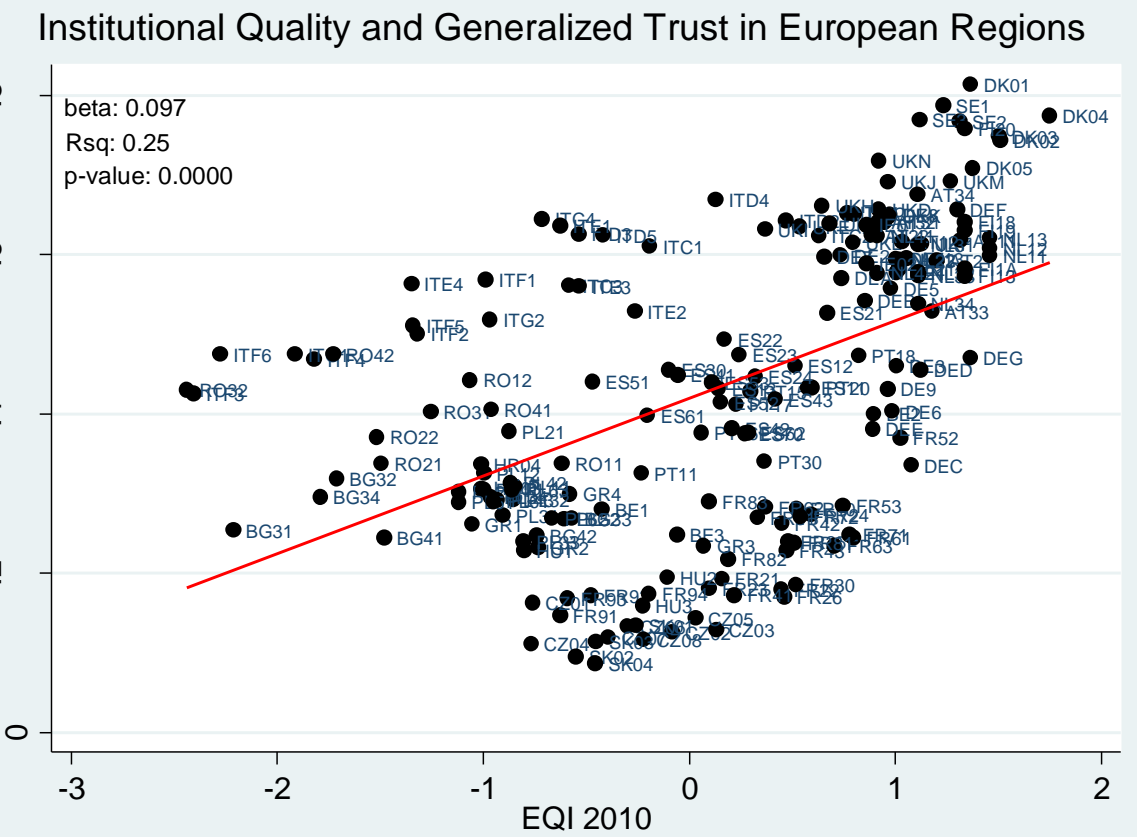


Table A1: Summary Statistics

\begin{tabular}{lcccccl}
\multicolumn{1}{c}{ Variable } & Obs & Mean & Std. Dev. & Min & Max & \\
\hline TRUST & 212 & 0.43 & 0.191 & 0.06 & 0.81 & author \\
EQI (2010) & 189 & 0.12 & 0.942 & -2.44 & 1.75 & Charron, Lapuente and Rothstein (2013) \\
noneuborn & 183 & 5.64 & 5.400 & 0.00 & 30.06 & Eurostat \\
lognonEUbrn & 182 & 0.97 & 1.630 & -3.91 & 3.40 & Eurostat (author created) \\
civicindex & 111 & 0.06 & 0.051 & 0.00 & 0.25 & European Value Survey, (author created) \\
STlifeex & 189 & 0.00 & 1.000 & -2.53 & 1.39 & Eurostat (author created) \\
povrisk & 181 & 16.17 & 6.713 & 4.90 & 38.40 & Eurostat \\
loggdp & 189 & 9.89 & 0.627 & 7.95 & 11.01 & Eurostat \\
LogPopDens & 189 & 2.50 & 1.647 & -0.02 & 8.49 & Eurostat \\
autonomous & 212 & 0.08 & 0.279 & 0.00 & 1.00 & author coded \\
capitalreg n & 212 & 0.11 & 0.318 & 0.00 & 1.00 & author coded
\end{tabular}


